\title{
The Roles of MicroRNAs and Extracellular Vesicles in the Pathogeneses of Idiopathic Pulmonary Fibrosis and Acute Respiratory Distress Syndrome
}

\author{
Mitsuhiro Yamada ${ }^{1}$ \\ ${ }^{1}$ Department of Respiratory Medicine, Tohoku University Graduate School of Medicine, Sendai, Miyagi, Japan
}

The lungs are the organs that work for gas exchange. The basic structure of the lungs is an alveolus, which consists of various types of parenchymal cells and bone marrow-derived cells. Therefore, because the lungs consist of various types of cells with various functions, communication among the different types of the cells should play important roles for the homeostasis and response to disease pathogens. In the past decades, researchers have focused on cytokines or adhesion molecules to reveal the intercellular communication for understanding the homeostasis and pathogenesis in the lungs. Recent investigations have revealed that an extracellular vesicle can move among cells for transferring substances including microRNAs in the vesicles as an intercellular messenger. MicroRNAs and extracellular vesicles are therefore attracting increasing attention from both translational and clinical researchers because these emerging intercellular communication tools seem to be useful for further understanding of the disease pathogenesis as well as the biomarkers for diagnosis and prognosis of the diseases including cancer and inflammatory diseases. This review article is an attempt to review studies about microRNAs and extracellular vesicles in terms of their roles in normal conditions and refractory diseases of the lungs such as idiopathic pulmonary fibrosis and acute respiratory distress syndrome including our recent study about pulmonary microvascular endothelial microparticles particles as the biomarker for diagnosis and prognosis of acute respiratory distress syndrome. This review also addresses the possibility of microRNAs and extracellular vesicles as new clinical tools for the diagnosis or treatment for these refractory respiratory diseases.

Keywords: ectosomes; exosome; extracellular vesicles; microparticle; microRNAs

Tohoku J. Exp. Med., 2020 August, 251 (4), 313-326.

\section{Introduction}

The lungs are the primary organs in the respiratory system. The main function of the lungs is gas exchange, to extract oxygen from the atmosphere and emit carbon dioxide from the blood into the atmosphere. The basic structure of the lungs is an alveolus, which consists of parenchymal cells including epithelial cells, endothelial cells and mesenchymal cells. Moreover, various types of bone marrowderived cells, including alveolar macrophages, exist in the alveoli and perform various functions including hostdefense and tissue repair. Therefore, because the lungs consist of various types of cells with various function, the communication among various types of cells should play important roles for maintaining the homeostasis as well as the pathogenesis of the diseases in the lungs (Zemans et al. 2015). Researchers have continuously made efforts to understand the intercellular communication, with focusing on molecules including cytokines, growth factors and cell adhesion molecules on the cell surface. In addition to these molecules, accumulating evidence suggests that an extracellular vesicle (EV) and its components including microRNAs, mRNA, lipids and proteins can move among cells for transferring components in the vesicles as intercellular messengers (Al-Nedawi et al. 2008; Delorme-Axford et al. 2013; Yáñez-Mó et al. 2015; Boilard 2018; Chen et al. 2018; Pegtel and Gould 2019). Therefore, both translational and clinical researchers pay increasing attention to

Received May 27, 2020; revised and accepted July 15, 2020. Published online August 7, 2020; doi: 10.1620/tjem.251.313.

Correspondence: Mitsuhiro Yamada, Department of Respiratory Medicine, Tohoku University Graduate School of Medicine, 1-1 Seiryomachi, Aoba-ku, Sendai, Miyagi 980-8574, Japan.

e-mail: yamitsu@med.tohoku.ac.jp

Dr. Mitsuhiro Yamada is a recipient of the 2019 Gold Prize, Tohoku University School of Medicine.

(C)2020 Tohoku University Medical Press. This is an open-access article distributed under the terms of the Creative Commons Attribution-NonCommercial-NoDerivatives 4.0 International License (CC-BY-NC-ND 4.0). Anyone may download, reuse, copy, reprint, or distribute the article without modifications or adaptations for non-profit purposes if they cite the original authors and source properly.

https://creativecommons.org/licenses/by-nc-nd/4.0/ 
microRNAs and EVs, as possible biomarkers for the diagnosis and prognosis of diseases, including malignant diseases as well as acute or chronic inflammatory diseases like idiopathic pulmonary fibrosis (IPF) and acute respiratory distress syndrome (ARDS). This review first attempts to describe the microRNAs and EVs in terms of their roles in the physiological condition in the lungs. Then, articles about the changes and possible roles during IPF and ARDS are reviewed. Both the possibilities and limitations of their clinical usage for the diagnosis and treatment of these refractory lung diseases will also be discussed.

\section{MicroRNAs and Their Physiological Roles in the Lungs}

MicroRNA is one of the classes of non-coding RNAs (ncRNA), discovered in 1993 in a study about the gene lin-4 of Caenorhabditis elegans (C. elegans) (Lee et al. 1993). Although this first study suggested that microRNA encoded by lin-4 is a specific ncRNA of C. elegans to control the levels of expression of different genes, following studies revealed that microRNAs exist in a wide variety of organisms including human and have potential roles in both inhibiting the translation and degradation of mRNAs (Lagos-Quintana et al. 2001; Lau et al. 2001; Lee and Ambros 2001; Bushati and Cohen 2007). In the microRNA database, miRBase, over 1,900 microRNAs have been registered as human microRNA, (Kozomara et al. 2019). MicroRNA is a single-strand RNA the length of which is nineteen to twenty-five nucleotides (Bushati and Cohen 2007). MicroRNA genes are initially transcribed by RNA polymerase II into an RNA stem-loop that contains a several hundred nucleotide microRNA precursor termed a primary microRNA (pri-microRNA) (Cai et al. 2004; Lee et al. 2004). A pri-microRNA contains a few precursors of microRNA. The structure of the precursor is a hairpin loop that consists of about 70 nucleotides (Cai et al. 2004; Lee et al. 2004). The double-stranded RNA structure of the hairpin loop of a pri-microRNA is recognized via protein, DiGeorge Syndrome Critical Region 8 (DGCR8), which is named based on the association with DiGeorge Syndrome. DGCR8 associates with the RNase III enzyme Drosha that cuts RNA (Lee et al. 2002; Han et al. 2004; Yeom et al. 2006). This complex cleaves the stem of a pri-microRNA and then produces pre-microRNAs that have a two-nucleotide overhanging at its 3' end. Then, Exportin-5 recognizes pre-microRNAs through the overhang and exports from the nucleus to the cytoplasm (Kim 2004). The hairpin of PremiRNA is cleaved by the RNase III enzyme Dicer in the cytoplasm. This cleaving produces an imperfect microRNA:microRNA* duplex, the length of which is 22 nucleotides (Hutvagner et al. 2001; Ketting et al. 2001). Although either strand can become a functional microRNA, only one strand is usually incorporated into the RNAinduced silencing complex (RISC) in which the microRNA and its target mRNA are interacting (Ketting et al. 2001, Schwarz et al. 2003). The other strand, which is called the passenger strand due to its lower levels of expression, is denoted with an asterisk $(*)$ and is usually degraded. In some cases, both strands (a microRNA and a microRNA*) of the duplex are viable and become functional miRNA that target different mRNA populations. MicroRNAs work for RNA silencing and post-transcriptional regulation of gene expression via base-pairing with complementary sequences within mRNA molecules (Bartel 2009; Djuranovic et al. 2011; Shukla et al. 2011). MicroRNAs downregulate mRNA expression through cleavage of the target mRNAs (Park and Shin 2014), destabilization via shortening of its poly(A) tail (Rissland et al. 2017), or interfering with the translation of mRNAs (Valencia-Sanchez et al. 2006).

As mentioned above, microRNAs can regulate the expression of endogenous genes. Therefore, proper regulation of microRNAs contributes to adequate gene expression, which maintain normal development and homeostasis in the organs including lungs. Continuous investigations by researchers have attempted to elucidate the roles of microRNAs in normal development and maturation of the lungs. For example, the miR-17-92 cluster is highly expressed during the early stage of lung development, but the expression of these microRNAs is downregulated during lung maturation ( $\mathrm{Lu}$ et al. 2007). Transgenic mice in which these microRNAs in lung epithelial cells are overexpressed resulted in abnormal lung, which suggests that miR-17-92 cluster promotes proliferation and prevents the differentiation of lung epithelial progenitor cells ( $\mathrm{Lu}$ et al. 2007). The upregulation of miR-21 in the mesenchyme is essential for branching morphogenesis, which is a critical process of lung development (Hayashi et al. 2011). miR-326 plays a role in negative feedback for regulating Sonic hedgehog signaling via downregulating its receptor Patched/ Smoothened in mesenchymal cells for proper proliferation and differentiation during lung development (Jiang et al. 2014). A recent report suggests the involvement of microRNAs in the regulation of trans-differentiation of alveolar type II (AT II) cells to alveolar Type I (AT I) cells, which is a critical process for repairing an injury and maintaining homeostasis in the lungs (Castaldi et al. 2020). The authors investigated the expression profiles of both microRNAs and mRNAs during trans-differentiation of AT II cells to AT I cells. They revealed that serum/glucocorticoid kinase 1 (SGK1) was downregulated by miR-424 and miR-503 that are upregulated during the trans-differentiation, which inhibited glucocorticoid signaling and induced the differentiation to AT I cells (Castaldi et al. 2020).

In contrast, dysregulation of microRNAs would induce inadequate expression of the genes, which could result in the development of diseases. In the following sections, this review introduces investigations together with discussions about the roles of microRNAs, especially in two severe and refractory diseases, IPF and ARDS.

\section{The Roles of MicroRNAs in the Pathogenesis of IPF}

The occasional deposition of collagen after tissue 
injury or inflammation is an essential and reversible reaction for normal tissue repair (Vannella and Wynn 2017). However, when the injury is repetitive or severe and when the machinery for tissue repair is impaired and/or dysregulated, persistent and massive accumulation of myofibroblasts and their production of extracellular matrix materials including collagen, has occurred, which results in the development of fibrotic diseases such as IPF (Richeldi et al. 2017; Sgalla et al. 2018; Heukels et al. 2019).

It has been reported that the levels of microRNAs are significantly changed in the lungs during both an animal model of lung fibrosis and human lung fibrotic diseases. In addition, the following reports also suggest that these microRNAs have roles in the proliferation and differentiation of myofibroblast and the epithelial-mesenchymal transition (EMT) during lung fibrosis. The levels of expression of let-7d are relatively high in lung epithelial cells under normal physiological conditions, but down-regulated in the lungs of the patients with IPF (Pandit et al. 2010). Transforming growth factor- $\beta$ (TGF- $\beta$ ), which is one of the key cytokines in the pathogenesis of IPF, inhibits let-7d expression, and the downregulation of let-7d by intratracheal administration of the anti-miRNA oligonucleotides induced both EMT and an increase in the deposition of collagen in the mouse lungs (Pandit et al. 2010).

A family of microRNAs, the miR-200 family, can reverse EMT and upregulate the markers of an epithelial phenotype in lung epithelial cell lines (Gregory et al. 2008; Liu et al. 2018). The miR-200 family downregulates the expression of ZEB proteins, ZEB1 and ZEB2, that work as repressors of the transcription. ZEB proteins suppress the expression of marker genes of epithelium including E-cadherin and induce EMT (Gregory et al. 2008; Title et al. 2018). The overexpression of miR-200s suppressed ZEB protein expression, which results in the induction of epithelial differentiation in cancer cell lines (Gregory et al. 2008; Title et al. 2018). The miR-200 family also inhibits EMT induced by TGF- $\beta$ in rat alveolar epithelial cells (Yang et al. 2012). We also found that the miR-200 family is downregulated in the lung epithelial cells of patients with IPF (Yamada et al. 2013). In a recent report, Moimas et al suggested that the miR-200 family could reduce the cellular senescent phenotype as well as the expression of EMT markers in AT II cells isolated from the lungs of IPF patients (Moimas et al. 2019). The miR-200 family could also restore the AT II ability of trans-differentiation into AT I cells (Moimas et al. 2019).

miR-21 was identified as a microRNA that functions as an anti-apoptotic factor against glioblastomas (Chan et al. 2005). Then, the following reports suggest that miR-21 works as an oncogenic microRNA by targeting tumor suppressors, including PTEN (Pan et al. 2010). miR-21 also has a role in the pathogenesis of lung fibrotic diseases. miR-21 is upregulated in the whole lung tissue of a bleomycin-induced mouse lung fibrosis model (Liu et al. 2010) as well as in the lung tissues of the patients with IPF (Liu et al.
2010; Cho et al. 2011; Oak et al. 2011). It has been reported that miR-21 is upregulated by TGF- $\beta 1$ and inhibits the expression of an inhibitory Smad, Smad7 (Liu et al. 2010). Therefore, miR-21 augments the signaling of TGF- $\beta$ signaling in a positive feedback manner.

Although miR-21 expression was primarily upregulated in myofibroblasts (Liu et al. 2010), we postulated that miR-21 could play a significant role in the EMT of lung epithelial cells during lung fibrosis because TGF- $\beta$ signaling is critical for inducing EMT. In our study, we first found that the epithelial cells of the lungs of a bleomycininduced mouse lung fibrosis model showed decreased expression of epithelial marker genes, whereas the expression of mesenchymal marker genes was increased. miR-21 was significantly upregulated in isolated mouse lung epithelial cells of a bleomycin-induced lung fibrosis model (Yamada et al. 2013). We then isolated lung epithelial cells from the lung tissue of the patients with idiopathic pulmonary fibrosis (Fig. 1A) and examined the expression of miR-21, which revealed an elevation of the expression level of miR-21 compared to control, shown in (Fig. 1B) (Yamada et al. 2013). MiR-21 was also upregulated in primary mouse lung epithelial cells cultured under the conditions that enhance EMT. Administration of the inhibitor against miR-21 prevented the upregulation of vimentin and alpha-smooth muscle actin in mouse lung epithelial cells under the culture conditions for EMT (Yamada et al. 2013). Our study suggests that miR-21 is also increased in lung epithelial cells, and promotes EMT and contributes to the pathogenesis of lung fibrosis (Yamada et al. 2013).

miR-101, which is downregulated in the lungs of IPF patients and in a mouse lung fibrosis model, inhibits the proliferation and activation of lung fibroblasts by targeting Frizzled receptor $4 / 6$ and TGF- $\beta$ receptor 1 (Huang et al. 2017). The expression of miR-29b in cultured lung epithelial cells is downregulated by silica, which can induce lung fibrosis. The administration of miR-29b can inhibit EMT and the progression of fibrotic changes in a mouse model of silica-induced lung fibrosis (Sun et al. 2019). Accumulating evidence suggests the significant involvement of microRNAs in the pathogenesis of IPF (Miao et al. 2018; Barnes et al. 2019), which implies that these microRNAs may be candidate target molecules for developing future treatments for IPF.

\section{The Changes and the Roles of MicroRNAs in ARDS}

Acute respiratory distress syndrome (ARDS) is a syndrome that consists of non-cardiac pulmonary edema by increased pulmonary permeability resulting from severe invasive disease, such as severe pneumonia or sepsis (Confalonieri et al. 2017). The pathological changes in lung alveoli of patients with ARDS disrupts the barrier between alveolar and capillary endothelium caused by injuries of both lung epithelial and endothelial cells (Matthay and Zimmerman 2005; Bhattacharya and Matthay 2013). Direct ARDS is a lung injury caused by local lung damage 
A

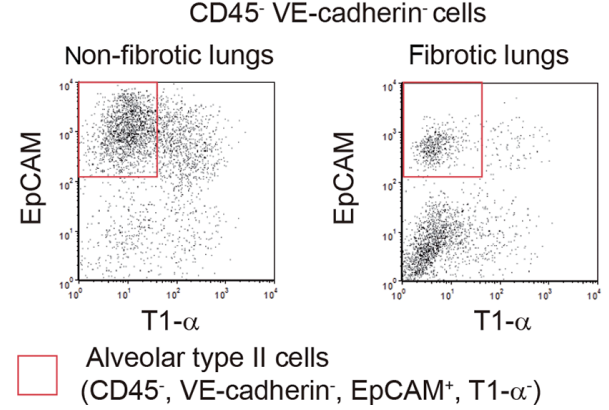

B

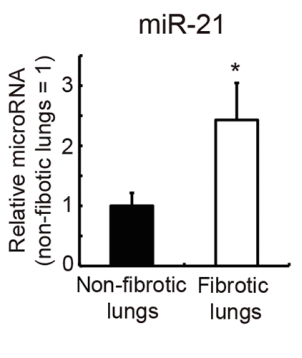

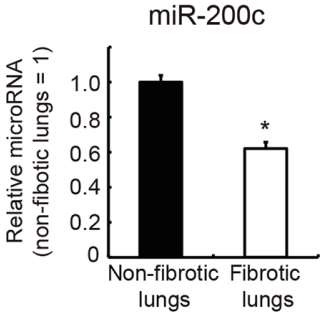

Fig. 1. The changes of microRNAs in alveolar type II cells in IPF.

(A) Representative flow cytometric analyses of CD45- VE-cadherin- lung cells for the isolation of human alveolar type II cells (CD45- VE-cadherin- EpCAM+ T1- $\alpha$ - cells) from the non-fibrotic lungs of patients without fibrotic lung diseases and the fibrotic lungs of patients with IPF. (B) The relative expression of microRNAs is shown. The values represent the mean \pm SEM $(n=3)$. The values relative to those of the human alveolar type II cells from non-fibrotic lungs are presented. The data were analyzed with Student's t-test.

" $\mathrm{p}<0.05$ vs. the non-fibrotic lung group.

The figure is reproduced from our article published in Respir. Res. (Yamada et al. 2013) with permission.

such as pneumonia and aspiration (Shaver and Bastarache 2014). In contrast, indirect ARDS is a lung injury caused by systemic disorders, such as sepsis and severe trauma that damage the alveolar capillary endothelium (Shaver and Bastarache 2014). The disruption mechanisms of the alveolar-capillary barrier are different between direct and indirect ARDS. Experiments using animal models suggest that injury of the epithelium is greater in direct ARDS (Menezes et al. 2005), whereas endothelial injury is dominant in indirect ARDS (Pelosi et al. 2003). Clinical reports also suggested that patients with direct ARDS showed an increase in the levels of both surfactant protein D (SP-D) and soluble receptor for advanced glycation end product (sRAGE), which are markers of pulmonary epithelial injury. Indirect ARDS patients showed an increase in angiopoietin-2 (Ang2 ), which is a marker of endothelial injury (Calfee et al. 2015).

Several studies that profiled microRNAs in the blood of patients with ARDS were also performed and reported. Zhu et al. (2016) performed a survival analysis to seek the prognostic microRNAs in blood as part of the Molecular Epidemiology Study of ARDS (MEARDS) from the ICU at Massachusetts General Hospital and Beth Israel Deaconess Medical Center. They collected blood samples from 78 patients with moderate and severe ARDS and estimated the hazards ratio of microRNA for the 28-day mortality. They revealed that 19 microRNAs were associated with survival. Among them, five microRNAs were most differentially expressed, miR-628.3p $(\mathrm{HR}=1.70, \mathrm{p}<0.01), \operatorname{miR}-922$ $(\mathrm{HR}=1.05, \mathrm{p}<0.01), \operatorname{miR}-505^{*}(\mathrm{HR}=1.65, \mathrm{p}<0.01)$, miR-130b* $(\mathrm{HR}=1.44, \mathrm{p}<0.01)$, and miR-624 $(\mathrm{HR}=$ $1.38, \mathrm{p}<0.01)$. Moreover, according to statistical analyses, they determined the microRNA classifier that predicted the ARDS 28-day mortality and revealed that the time until death was shorter in patients with higher eight-miRNA classifier expression $(\mathrm{p}=0.04)$.

The same group also reported analyses that compared
microRNA expression in whole blood samples from patients with ARDS and critically ill at-risk control patients (Zhu et al. 2017). They revealed that the levels of miR181a or miR-92a were positively correlated with a risk for the development of ARDS, whereas miR-424 was negatively correlated with a risk for ARDS. The addition of these microRNAs to the Lung injury prediction Score can improve the estimation for the risk of developing ARDS. Although these reports did not investigate the mechanisms of the increase or decrease in the microRNA in patients with ARDS, and some of the microRNAs suggested in these human studies showed a different pattern of expression in animal models of ARDS, these studies may suggest that circulating microRNAs are potential biomarkers for the diagnosis or prognosis of ARDS.

Investigations for the role of microRNAs in the pathogenesis of ARDS have mainly used in vitro culture models and animal models (Table 1). Cai et al. (2012) investigated lipopolysaccharide (LPS)-induced mouse acute lung injury model and found that miR-214 and miR-415 were upregulated in the lungs during LPS-induced acute lung injury, whereas miR-16, miR-23a, miR-24, miR-181a, miR-181b and miR-199a were significantly downregulated. They focused on miR-16, which was one of the most significantly down-regulated microRNAs during LPS-induced lung injury, and performed an over-expression of miR-16 assay in LPS-treated A549 cells, an alveolar epithelial cell line. Over-expression of miR-16 significantly down-regulated the levels of expression of IL- 6 and TNF- $\alpha$. They also noted that a 3'-untranslated region (UTR) of IL-6 and TNF- $\alpha$ contains the binding sites of miR-16. According to this bioinformatics information, miR-16 significantly suppressed the luciferase activity of a reporter fusion vector with the TNF- $\alpha$ 3'UTR region, suggesting that miR-16 has an anti-inflammatory function by suppressing the translation of inflammatory cytokines. It has been also reported that miR-181b suppressed importin-alpha3, a protein that is 
Table 1. The roles of microRNAs in the pathogenesis of acute lung injury.

\begin{tabular}{|c|c|c|c|}
\hline microRNA & Change in acute lung injury & Function & References \\
\hline $\operatorname{miR}-16$ & Decreased & Suppression of IL- 6 and TNF- $\alpha$ expression & (Cai et al. 2012) \\
\hline $\operatorname{miR}-181 \mathrm{~b}$ & Decreased & $\begin{array}{l}\text { Suppression of Importin- } \alpha 3 \text { expression } \\
>\text { Inhibition of NF- } \kappa \text { b nuclear translocation } \\
>\text { Suppression of the expression of target genes of NF- } \kappa b \\
>\text { Suppression of inflammation }\end{array}$ & $\begin{array}{l}\text { (Cai et al. 2012; } \\
\text { Sun et al. 2012) }\end{array}$ \\
\hline miR-155 & Increased & $\begin{array}{l}\text { Suppression of SOCS1 expression } \\
>\text { Enhancement of cytokine signaling }\end{array}$ & (Rao et al. 2014) \\
\hline miR-146a & Increased & $\begin{array}{l}\text { Suppression of IRAK- } 1 \text { and TRAF- } 6 \text { expression } \\
>\text { Inhibition of NF- } \kappa \text { b activation } \\
>\text { Suppression of expression of inflammatory cytokines }\end{array}$ & (Zeng et al. 2013) \\
\hline miR-223 & $\begin{array}{l}\text { Increased } \\
\text { (transferred from PMNs to } \\
\text { alveolar epithelial cells) }\end{array}$ & $\begin{array}{l}\text { Suppression of PARP- } 1 \text { expression } \\
>\text { Inhibition of NF- } \kappa \text { b and AP-1activation } \\
>\text { Suppression of inflammation }\end{array}$ & (Neudecker et al. 2017) \\
\hline
\end{tabular}

required for the nuclear translocation of NF- $\kappa \mathrm{B}$, and regulates the expression adhesion molecules induced by inflammatory stimuli through NF- $\kappa$ B (Sun et al. 2012). These studies suggest that microRNAs that can inhibit the translation of inflammatory cytokines were downregulated during ARDS, resulting in the aggravation of inflammation.

Rao et al. (2014) focused on miR-155, which was upregulated in the lung-infiltrating mononuclear cells in an acute lung injury model, and analyzed the role of miR-155 in acute lung injury using miR-155 deficient mice. They prepared an acute lung injury model induced by staphylococcal enterotoxin B (SEB) using wild-type mice and miR155 deficient mice. They found a decrease in the infiltration of inflammatory cells, especially $\mathrm{T}$ lymphocytes, in miR-155 deficient mice. Because the expression of interferon- $\gamma$ (IFN- $\gamma$ ) also decreased, they investigated the signaling pathway related to IFN- $\gamma$ and revealed that suppressor of cytokine signaling 1 (SOCS1), a negative regulator of IFN- $\gamma$, was upregulated in miR-155 deficient mice. These findings suggest the possibility that miR-155 suppressed the expression of SOCS1 protein and augmented the signaling induced by cytokines during acute lung injury.

It has been reported that miR-146a, which is also upregulated in a LPS-induced acute lung injury animal model, suppresses inflammatory responses (Zeng et al. 2013). miR-146a significantly suppressed LPS-mediated TNF- $\alpha$, IL- 6 and IL-1 $\beta$ induction in alveolar macrophage cells through repressing the protein expression of IRAK-1 (IL-1 receptor activated kinase-1) and TRAF-6 (tumor receptor factor associated factor-6), which results in the activation of NF- $\kappa \mathrm{B}$. It was also reported that miR-146a also contributed to the induction of M2 macrophages, antiinflammatory macrophages (Vergadi et al. 2014). These observations may suggest that miR-146a plays a significant role in regulation of inflammation during ARDS.

Polymorphonuclear neutrophil (PMN) is a key player in lung tissue damage during ARDS, whereas it has been suggested that neutrophils also contribute to the resolution of inflammation and repair of alveolar epithelial cells (Zemans et al. 2011). Neudecker et al. (2017) reported an interesting study showing that neutrophils contributed to anti-inflammatory functions by transferring neutrophilderived microRNAs to pulmonary epithelial cells. They cocultured alveolar epithelial cells with PMNs and analyze the changes of expression of microRNAs in the alveolar epithelial cells. They found a selective increase of miR223. When they cocultured alveolar epithelial cells with miR-223-deficient PMNs, they did not find an increase of miR-223 in the epithelial cells, which suggested that PMNderived miR-223 became incorporated into the epithelial cells, but not by the induction of miR-223 in the epithelial cells by stimulation by humoral factors derived from PMNs. MiR-223 was increased both in the lung tissues of a ventilator-induced acute lung injury mouse model and in the bronchoalveolar lavage fluids of ARDS. They also revealed that miR-223 deficiency induced severer lung inflammation, whereas overexpression of miR-223 in mouse lungs resulted in protection in lung injury models. They further revealed that the target of miR-223 was poly (adenosine diphosphate-ribose) polymerase-1 (PARP-1), which augments inflammatory responses via the activation of NF- $\kappa$ B and AP-1 transcription factors, which suggested miR-223 suppressed inflammation by the downregulation of PARP1. These interesting findings suggest that miR-223 from neutrophils was transferred to pulmonary epithelial cells intracellularly and reduced the acute lung injury through the repression of PARP-1.

Accumulating evidence including the above-mentioned studies have revealed that microRNAs play important roles in not only the regulation of expression and translation of the genes in the cells, but also in the intercellular regulation of the expression during acute lung injury, suggesting that microRNA has an important role in ARDS and could be a candidate of the biomarker for the diagnosis and prognosis as well as a target molecule for a new treatment for ARDS.

\section{Extracellular Vesicles and Their Role in the Lungs under Physiological Conditions}

Extracellular vesicles (EVs) are lipid bilayer-particles 
produced and secreted from variety types of cells (Yáñez-Mó et al. 2015). EVs can be broadly classified into three classes, apoptotic bodies, microparticles and exosomes according to their size, biogenesis, transportation, cellular source, and function (Gyorgy et al. 2011; Yanez-Mo et al. 2015; Witwer and Thery 2019). Apoptotic bodies are released as blebs of plasma membrane from cells that undergo apoptosis (Yáñez-Mó et al. 2015). Microparticles, which are also called as microvesicles or ectosomes, are vesicles produced by outward budding of the plasma membrane (Yáñez-Mó et al. 2015). Exosomes, which are one of the major components of EVs, are formed in the endosomal system and released from the cells via the fusion of multivesicular-bodies with the plasma membrane (Raposo and Stoorvogel 2013; Yáñez-Mó et al. 2015) (Fig. 2). Because it has been revealed that exosomes contain various bioactive materials including microRNAs, exosomes have been considered as novel intercellular communication tools (Valadi et al. 2007; Yáñez-Mó et al. 2015) (Fig. 2). Several studies demonstrated that microRNAs in exosomes can be transferred to other cells to regulate the expression of the targeted genes (Kosaka et al. 2010; Pegtel et al. 2010; Zhang et al. 2010). Exosomes and enveloped microRNAs have been shown to have functions in both physiological and pathological conditions (Candelario and Steindler 2014; Kosaka et al. 2014; Waldenstrom and Ronquist 2014; Lai et al. 2015; Nishida-Aoki and Ochiya 2015). Exosomes and enveloped microRNAs within biological fluids, such as circulating blood or urine, have also attracted attention from both clinical and translational researchers as novel biomarkers of diseases, especially malignant diseases, because the components and secretion dynamics of exosomes vary according to the cellular origin as well as the environment (Vlassov et al. 2012; Yoshioka et al. 2013).

EVs including exosomes exist abundantly in biological fluid samples from the airway, such as broncho-alveolar lavage fluid (BALF), even under physiological conditions (Carnino et al. 2019), which may suggest that EVs have a role in the maintenance of the respiratory system. The exosomes derived from lung epithelial cells have a variety of surface proteins including mucins that can bind pathogens such as bacteria and virus, which suggests their possible role in host defence (Kesimer et al. 2009). Alveolar macrophages produce the exosomes that contains SOCS1 and microparticles that contains SOCS3 (Bourdonnay et al. 2015). These EVs are incorporated into alveolar epithelial cells, which results in the inhibition of cytokine signalling (Bourdonnay et al. 2015). These findings suggest the roles of EVs from alveolar macrophages in regulating the cytokine responses and homeostasis of alveolar epithelial cells. The EVs derived from alveolar macrophages can also transfer miR-223 to a variety of cells including parenchymal cells and monocytes, and can induce the differentiation of monocytes into alveolar macrophages (Ismail et al. 2013). These reports suggest that the EVs from lung-resident cells may participate in host defence and homeostasis in the lungs. It has been reported that the amount and contents of EVs such as microRNAs may vary according to environmental and endogenous stress (Yáñez-Mó et al. 2015). Therefore, studies to profile EVs in the extracellular fluids of patients with lung diseases or animal models of lung diseases, have been performed in the attempt to identify the specific EVs and/or the specific contents of EVs that can work as biomarkers for the diagnosis or prognosis of diseases as well as for determining their possible participation in the pathogenesis of lung diseases. In the following sections, I introduce the studies, including ours, that analyzed EVs in animal models and in patients of lung fibrosis and ARDS.

\section{The Changes and the Roles of EVs in IPF}

We examined the possibility that microRNAs in the EVs of serum changed during lung fibrosis and could serve as biomarkers for the prognosis of IPF (Makiguchi et al. 2016). To identify candidate microRNAs as the biomarkers of IPF, we examined microRNA expression profiles in serum EVs using microRNA PCR arrays in a bleomycininduced mouse lung fibrosis model. We validated the candidate microRNAs detected by the arrays using RT-PCR in additional mice. Serum EV miR-21-5p was elevated in
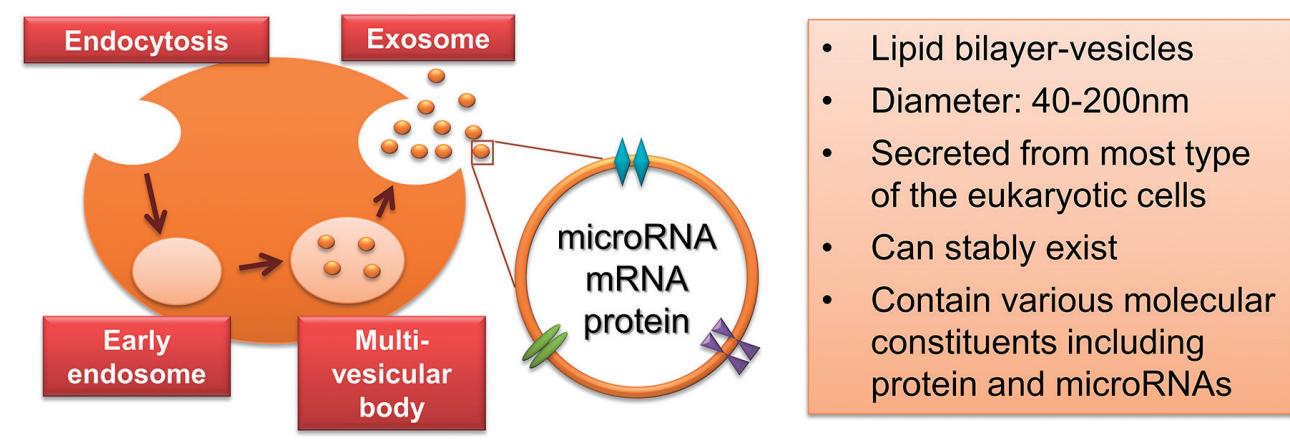

Fig. 2. Generation of Exosomes

Exosomes are derived from the endosomal compartment of cells. It has been reported the molecules related to endocytosis including Rab small G protein family and ESCRT (endosomal sorting complexes required for transport) are involved in the generation and secretion of exosomes, although the mechanism has not been fully elucidated. 
both the acute phase and the chronic fibrotic phase. Then, we performed a 30-month prospective cohort study with 41 IPF patients. The levels of miR-21-5p in serum EV were normalized by dividing the relative amounts of EV. The EV amount was detected by ExoScreen (Yoshioka et al. 2014). The levels of serum EV miR-21-5p was significantly higher in IPF patients. The baseline level was correlated with the decline in vital capacity over 6 months. Serum EV miR-21-5p was independently associated with mortality in the following 30 months. The survival analysis showed that IPF patients whose levels of baseline serum
miR-21-5p were high resulted in a poorer prognosis during the 30 months (Fig. 3). Our study suggests that the serum levels of EV miR-21-5p at baseline can predict both the short-term disease progression in terms of the decline in vital capacity and long-term prognosis in terms of mortality in IPF patients. The precise mechanism of the increase in the serum EV miR-21-5p in IPF patients is still unclear. However, because the expression of miR-21-5p is upregulated by TGF- $\beta$ signaling (Liu et al. 2010), the increase in the serum EV miR-21-5p level may reflect the conditions of IPF, in which TGF- $\beta$ signaling is one of the important sig-

A

$\operatorname{miR}-21-5 p$

(copies/SI)

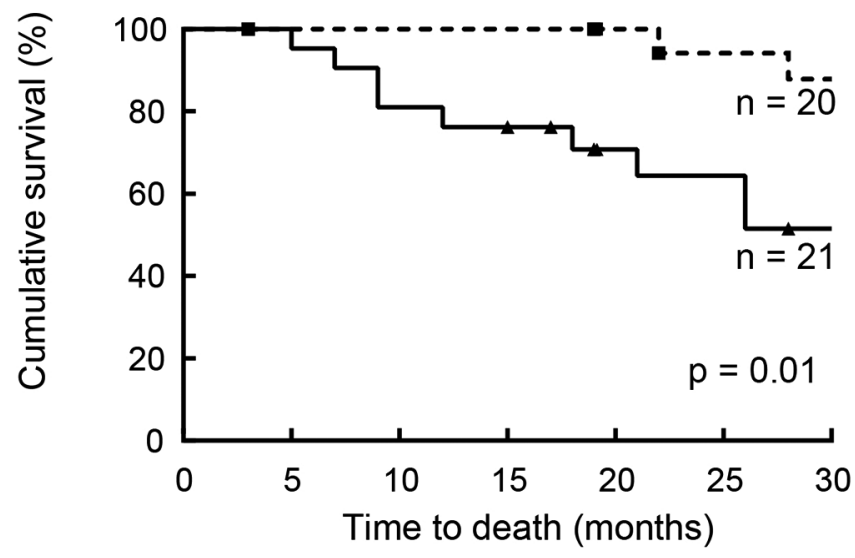

B
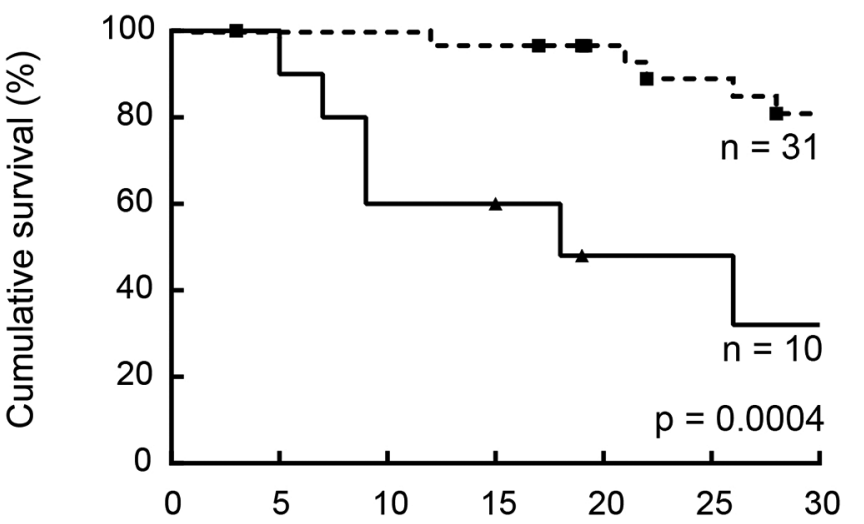

Time to death (months)

Fig. 3. Serum EV miR-21-5p levels are predictive of the mortality of IPF.

(A) The solid line shows the group of IPF patients that had baseline serum EV miR-21-5p levels above the median level of EV miR-21-5p (2.1 copies/SI). The dashed line shows the group of IPF patients that had baseline serum EV miR-21$5 p$ levels below the median level. The patients with the higher serum EV miR-21-5p levels showed higher mortality during the 30 -month follow-up period $(\mathrm{p}=0.01)$. (B) The solid line shows the group of IPF patients that had the topquartile baseline serum EV miR-21-5p levels ( $\geq 4$ copies/SI, $n=10)$. The dashed line shows the group of IPF patients that had baseline serum EV miR-21-5p levels below 4 copies/SI $(n=31)$. The patients who had serum EV miR-21-5p levels in the top-quartile showed higher mortality during the 30 -month follow-up period $(\mathrm{p}=0.0004)$. The dots represent cases that were censored because of failure to visit the hospital. The entire population $(\mathrm{n}=41)$ contained 9 censored patients. The figure is reproduced from our article published in Respir Res. (Makiguchi et al. 2016) with permission. 
naling pathways for the pathogenesis.

Martin-Medina et al. (2018) demonstrated that EVsmediated WNT5A signaling is upregulated in patients with IPF, which induces the proliferation and activation of lung fibroblasts and contributes to the pathogenesis of IPF. They found that EVs, especially exosomes, are increased in BALF from a mouse animal model of lung fibrosis as well as in IPF patients. The levels of WNT5A on EVs are upregulated during lung fibrosis. TGF- $\beta$ induces WNT5A expression on EVs secreted from human lung primary fibroblast. Both the EVs of human lung primary fibroblast and EVs from BALF of IPF patients induces the proliferation and activation of lung fibroblasts. Their investigation reveals that EVs are not only changed in their amounts and contents during lung fibrosis but also have a significant role in the pathogenesis of IPF.

\section{Extracellular Vesicles in ARDS}

Several studies have been reported about the changes in microRNA expression in lung injury models and the possibility of a new treatment strategy using exosomes for ARDS (Table 2). Zhu et al. (2014) showed that intratracheal instillation of exosomes which isolated in culture supernatants of human mesenchymal stem cells (MSCs) ameliorated lung injury in an Escherichia coli-derived LPSinduced lung injury model. Instillation of the exosomes induced a reduction in pulmonary edema and lung protein permeability as well as an influx of neutrophils. They further investigated the mechanism and revealed that KGF mRNAs in the exosomes played an important role in this amelioration of inflammation.

Morrison et al. (2017) focused on the paracrine effect of MSCs on macrophage polarization and the role of EV-mediated mitochondrial transfer. They cocultured human monocyte-derived macrophages (MDMs) with MSCs without direct contact. They found a decrease in the production of inflammatory cytokines and an increase in the cell surface expression of CD206, which is important for phagocytosis, and the ability of phagocytosis in the MDMs. These effects were partially mediated by CD44-expressing EVs that include exosomes. They also found that the treatment of MDMs with MSC-EVs induced mitochondrial transfer from the EVs to the MDMs. Adoptive transfer of alveolar macrophages treated with the exosomes derived from MSCs suppressed inflammation and lung injury in a LPS-induced lung injury model. This effect of MSCs was inhibited by blocking oxidative phosphorylation or generat- ing dysfunctional mitochondria in MSCs using rhodamine$6 \mathrm{G}$ pre-treatment. These findings suggest that the antiinflammatory effects of MSC-EVs depend on the EV-mediated mitochondrial transfer, which results in the enhancement of macrophage oxidative phosphorylation and change in the macrophage phenotype.

On the other hand, Moon et al. (2015) reported that the extracellular vesicles including exosomes derived from epithelial cells activated macrophages and augmented inflammation in an acute lung injury model. They found that, after hyperoxia, EVs were generated and released into BALF. These hyperoxia-induced EVs were mainly derived from lung epithelial cells because of hyperoxia-associated endoplasmic reticulum stress. Treating alveolar macrophages with hyperoxia-induced, epithelial cell-derived EVs induced an increase in the secretion of IL-6, TNF- $\alpha$ and macrophage inflammatory protein 2 (MIP-2). They further investigated the mechanism and revealed that caspase- 3 in EVs was largely responsible for the alveolar macrophage activation via the Rho-associated protein kinase (ROCK1) pathway. These results show that hyperoxia-induced, lung epithelial cell-derived and caspase-3 enriched EVs activate macrophages and augment the inflammatory responses during acute lung injury.

The evidence including that from studies shown in this section suggests the possibility that EVs derived from lung parenchymal cells activate inflammatory cells including lung macrophages, which results in exacerbation of the inflammation in ARDS. On the other hand, reports that MSC-derived EVs, including exosomes, reinforce previous findings about the anti-inflammatory function of MSCs during acute lung injury models and suggest that MSC-EVs could be a possible treatment for ARDS.

\section{Pulmonary Endothelial Microparticles in ARDS}

As mentioned briefly in the previous section, microparticles (MPs), also called microvesicles or ectosomes, are one of the classes of EVs whose dimensions are between $0.1 \mu \mathrm{m}$ and $1.0 \mu \mathrm{m}$ (Meziani et al. 2010; Burger et al. 2013). MPs are produced via outward blebbing and fission of the plasma membrane during injury, cell activation or apoptosis (Schiro et al. 2014; Yun et al. 2016). MPs have been used as the biomarker indicating injury of a specific type of cells because it is possible to identify their parent cells by analyzing the cell-specific antigen on the MP surface. It has been reported that MPs also participate in intercellular communication (Burger et al. 2013; Schiro et

Table 2. Extracellular vesicles/exosomes in acute lung injury.

\begin{tabular}{|c|c|c|c|}
\hline Origin & Functional molecules/apparatus & Function & References \\
\hline Bone-marrow derived MSCs & KGF mRNA & $\begin{array}{l}\text { Suppression of inflammatory } \\
\text { responses }\end{array}$ & (Zhu et al. 2014) \\
\hline Bone-marrow derived MSCs & Mitochondria & $\begin{array}{l}\text { Modulating differentiation of } \\
\text { alveolar macrophages }\end{array}$ & (Morrison et al. 2017) \\
\hline Lung epithelial cells & Caspase 3 & Activation of macrophages & (Moon et al. 2015) \\
\hline
\end{tabular}


al. 2014; Nie et al. 2016). Endothelial microparticles (EMPs), which are MPs derived from endothelial cells, increase in blood samples of patients with diseases accompanied by endothelial injury such as acute coronary syndrome, renal failure and COPD (Amabile et al. 2005; Faure et al. 2006; Kobayashi et al. 2007; Nozaki et al. 2009; Feng et al. 2010; Gordon et al. 2011; Jung et al. 2012; Takahashi et al. 2012, 2013; Suzuki et al. 2014). These findings led to our hypothesis that the EMPs could be a marker of the injury alveolar endothelial cells during ARDS. Analyzing the EMPs expressing a specific marker protein of the alveolar capillary endothelium is important to distinguish pulmonary microvascular injury from systemic capillary injury for utilizing EMPs as a biomarker for ARDS. We then focused on angiotensin converting enzyme (ACE), because alveolar capillary endothelial cells express relatively high levels of ACE compared with other endothelial cells (Danilov et al. 1994, 2001; Aird 2007). Therefore, we investigated whether circulating $\mathrm{ACE}^{+}$EMPs are increased in patients with ARDS and correlate with the severity of the microvascular injury in the lungs (Takei et al. 2019).

We first confirmed that inflammatory stimuli induce the formation of $\mathrm{ACE}^{+}$EMPs from primary pulmonary microvascular endothelial cells. We then examined circulating EMPs in direct and indirect ARDS mouse models by flow cytometry. The total EMP numbers in circulating blood were significantly increased (Fig. 4A). The numbers of $\mathrm{ACE}^{+}$EMPs were also increased in both injury models (Fig. 4B). The ratio of $\mathrm{ACE}^{+}$EMP/EMP also increased in both injury models (Fig. 4C), suggesting that the increase in the counts of $\mathrm{ACE}^{+}$EMPs in the lung injury models was likely due to the increase in the numbers of $\mathrm{ACE}^{+} \mathrm{EMPs}$ produced from lung alveolar endothelial cells. We also found that circulating $\mathrm{ACE}^{+} \mathrm{EMPs}$ and the $\mathrm{ACE}^{+} \mathrm{EMP} /$ EMP ratio were possibly correlated with the severity of lung injury.

Furthermore, we examined circulating $\mathrm{ACE}^{+}$EMPs by flow cytometry in septic patients. The counts of $\mathrm{ACE}^{+}$ EMPs on admission were significantly higher in the blood samples of septic patients who developed ARDS than in those who didn't ARDS (Fig. 4E), whereas no difference was observed in total counts of EMPs (Fig. 4D). The ratio of $\mathrm{ACE}^{+} \mathrm{EMP} / \mathrm{EMP}$ was also significantly higher in patients who developed ARDS (Fig. 4F). We also found that both circulating $\mathrm{ACE}^{+} \mathrm{EMP}$ counts and the ratio of $\mathrm{ACE}^{+} \mathrm{EMP} /$ EMP were higher in the patients that developed ARDS than in the patients with hydrostatic pulmonary edema. These findings suggested that alveolar EMPs may reflect the severity of the lung injury and can be a promising risk marker for developing ARDS in the septic patients as well as a diagnostic marker for ARDS to distinguish it from hydrostatic edema.

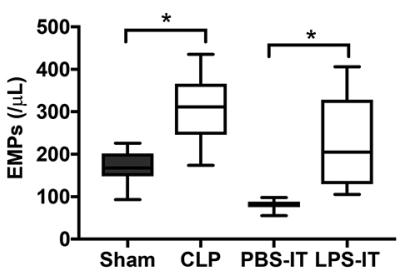

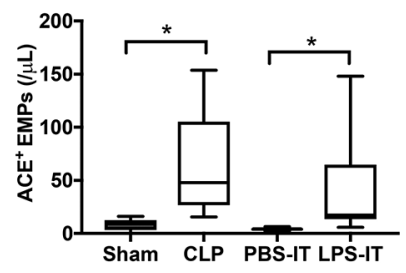

$\mathbf{E}$

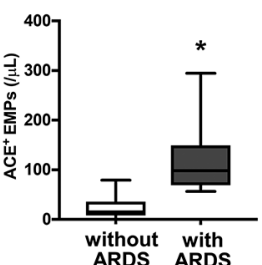

$\mathbf{F}$
C
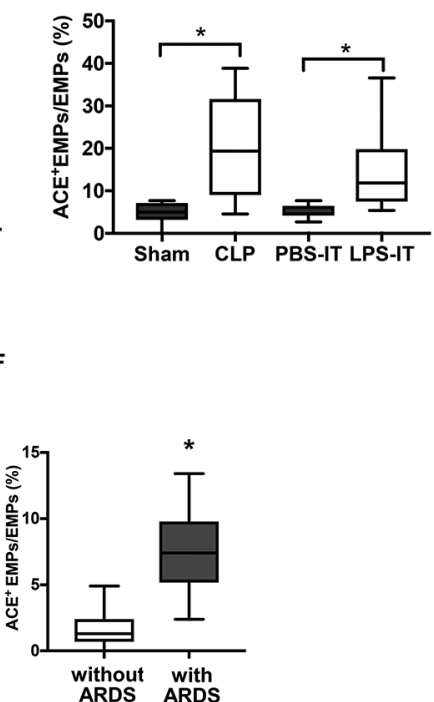

Fig. 4. Circulating $\mathrm{ACE}^{+}$EMPs are predictive of the development of ARDS in septic patients.

The counts of EMPs (A), $\mathrm{ACE}^{+}$EMPs (B) and the $\mathrm{ACE}^{+} \mathrm{EMP} / \mathrm{EMP}$ ratio (C) in sham-operated mice (sham), CLP-operated mice (CLP), intratracheal PBS-administered mice (PBS-IT) and intratracheal LPS-administered mice (LPS-IT; $\mathrm{n}=$ 12 in each group). Box and whisker plots show the first and third quartiles (bottom and top of the box), the median (the band inside the box), and the minimum and maximum (the ends of the whiskers).

ACE, angiotensin-converting enzyme; CLP, cecal ligation and puncture; EMPs, endothelial microparticles; LPS, lipopolysaccharide; PBS, phosphate-buffered saline; ARDS, acute respiratory distress syndrome.

" $\mathrm{p}<0.05$ between the two groups. The number of EMPs (D), $\mathrm{ACE}^{+}$EMPs (E) and the $\mathrm{ACE}^{+} \mathrm{EMP} / \mathrm{EMP}$ ratio $(\mathrm{F})$ in the serum of septic patients who developed (gray; $n=21$ ) or who did not develop ARDS (white; $n=61$ ).

The figure is reproduced from our article published in Eur. Respir. J. (Takei et al. 2019) with permission. 


\section{Perspective and Conclusion}

Recent investigations including the above-mentioned studies have elucidated the roles of microRNAs and extracellular vesicles in the pathogenesis and also suggests the possibility of circulating microRNAs and EVs serving as biomarkers for the diagnosis and prognosis of IPF and ARDS. However, there are significant issues that should be solved to elucidate their precise roles toward utilizing microRNAs and EVs for actual diagnosis and treatment. First, since most studies of microRNAs and EVs in IPF and ARDS are performed only in relatively small-sized patient cohort or animal models, high throughput analytical methods for many samples should be created for confirmation by large-scaled clinical trials for practical use. Recent advances in comprehensive high throughput analyses for microRNAs are enabling the diagnosis of various type of malignant diseases by analyzing the profile of circulating microRNAs in the blood (Yokoi et al. 2018; Asano et al. 2019; Ohno et al. 2019; Sudo et al. 2019). These technologies may be useful for diagnosing and predicting the prognosis of non-malignant diseases including IPF and ARDS. Second, although the analyses of each class of EVs should be performed with its detection and isolation in a rigorous way, most of the previous studies used various methods and strategies for the detection, isolation and analyses of EVs, which makes it difficult to compare the results among studies. The EVs are very small-sized particles that are still difficult to detect and isolate efficiently even using the present advanced technologies. Third, because EVs in biological fluids can be derived from various types of cells in the whole body of human, it should be important to detect and isolate organ-specific and/or cell-type specific EVs that are released from the sites of disorders for precise understanding of the pathogenesis of diseases as well as for the clinical use. Investigators continue to improve the technique for detecting specific EVs (Wang et al. 2020). Fourth, delivery methods for potentially therapeutic microRNAs and/or EVs to specific target cells or organ have not been well-established, though intensive investigations have been performed for solving this problem (Melling et al. 2019; Wiklander et al. 2019). Further investigations of microRNAs and EVs to overcome these issues could provide a new treatment strategy for refractory respiratory diseases including IPF and ARDS.

\section{Acknowledgments}

The author thanks Professor Emeritus Masakazu Ichinose, Prof. Hisatoshi Sugiura, and the members of the Department of Respiratory Medicine, Tohoku University Graduate School of Medicine in Sendai, Japan for precious advice and help in performing the studies mentioned in this review article. The author thanks Mr. Brent K. Bell for critical reading of the manuscript and language assistance.

\section{Conflict of Interest}

The author declares no conflict of interest.

\section{References}

Aird, W.C. (2007) Phenotypic heterogeneity of the endothelium: II. representative vascular beds. Circ. Res., 100, 174-190.

Al-Nedawi, K., Meehan, B., Micallef, J., Lhotak, V., May, L., Guha, A. \& Rak, J. (2008) Intercellular transfer of the oncogenic receptor EGFRvIII by microvesicles derived from tumour cells. Nat. Cell Biol., 10, 619-624.

Amabile, N., Guérin, A.P., Leroyer, A., Mallat, Z., Nguyen, C., Boddaert, J., London, G.M., Tedgui, A. \& Boulanger, C.M. (2005) Circulating endothelial microparticles are associated with vascular dysfunction in patients with end-stage renal failure. J. Am. Soc. Nephrol., 16, 3381-3388.

Asano, N., Matsuzaki, J., Ichikawa, M., Kawauchi, J., Takizawa, S., Aoki, Y., Sakamoto, H., Yoshida, A., Kobayashi, E., Tanzawa, Y., Nakayama, R., Morioka, H., Matsumoto, M., Nakamura, M., Kondo, T., et al. (2019) A serum microRNA classifier for the diagnosis of sarcomas of various histological subtypes. Nat. Commun., 10, 1299.

Barnes, P.J., Baker, J. \& Donnelly, L.E. (2019) Cellular senescence as a mechanism and target in chronic lung diseases. Am. J. Respir. Crit. Care Med., 200, 556-564.

Bartel, D.P. (2009) MicroRNAs: target recognition and regulatory functions. Cell, 136, 215-233.

Bhattacharya, J. \& Matthay, M.A. (2013) Regulation and repair of the alveolar-capillary barrier in acute lung injury. Annu. Rev. Physiol., 75, 593-615.

Boilard, E. (2018) Extracellular vesicles and their content in bioactive lipid mediators: more than a sack of microRNA. $J$. Lipid Res., 59, 2037-2046.

Bourdonnay, E., Zaslona, Z., Penke, L.R., Speth, J.M., Schneider, D.J., Przybranowski, S., Swanson, J.A., Mancuso, P., Freeman, C.M., Curtis, J.L. \& Peters-Golden, M. (2015) Transcellular delivery of vesicular SOCS proteins from macrophages to epithelial cells blunts inflammatory signaling. J. Exp. Med., 212, 729-742.

Burger, D., Schock, S., Thompson, C.S., Montezano, A.C., Hakim, A.M. \& Touyz, R.M. (2013) Microparticles: biomarkers and beyond. Clin. Sci. (Lond.), 124, 423-441.

Bushati, N. \& Cohen, S.M. (2007) microRNA functions. Annu. Rev. Cell Dev. Biol., 23, 175-205.

Cai, X., Hagedorn, C.H. \& Cullen, B.R. (2004) Human microRNAs are processed from capped, polyadenylated transcripts that can also function as mRNAs. RNA, 10, 19571966.

Cai, Z.G., Zhang, S.M., Zhang, Y., Zhou, Y.Y., Wu, H.B. \& Xu, X.P. (2012) MicroRNAs are dynamically regulated and play an important role in LPS-induced lung injury. Can. J. Physiol. Pharmacol., 90, 37-43.

Calfee, C.S., Janz, D.R., Bernard, G.R., May, A.K., Kangelaris, K.N., Matthay, M.A. \& Ware, L.B. (2015) Distinct molecular phenotypes of direct vs indirect ARDS in single-center and multicenter studies. Chest, 147, 1539-1548.

Candelario, K.M. \& Steindler, D.A. (2014) The role of extracellular vesicles in the progression of neurodegenerative disease and cancer. Trends Mol. Med., 20, 368-374.

Carnino, J.M., Lee, H. \& Jin, Y. (2019) Isolation and characterization of extracellular vesicles from Broncho-alveolar lavage fluid: a review and comparison of different methods. Respir. Res., 20, 240.

Castaldi, A., Horie, M., Rieger, M.E., Dubourd, M., Sunohara, M., Pandit, K., Zhou, B., Offringa, I.A., Marconett, C.N. \& Borok, Z. (2020) Genome-wide integration of microRNA and transcriptomic profiles of differentiating human alveolar epithelial cells. Am. J. Physiol. Lung Cell Mol. Physiol., 319, L173- 
L184.

Chan, J.A., Krichevsky, A.M. \& Kosik, K.S. (2005) MicroRNA-21 is an antiapoptotic factor in human glioblastoma cells. Cancer Res., 65, 6029-6033.

Chen, G., Huang, A.C., Zhang, W., Zhang, G., Wu, M., Xu, W., Yu, Z., Yang, J., Wang, B., Sun, H., Xia, H., Man, Q., Zhong, W., Antelo, L.F., Wu, B., et al. (2018) Exosomal PD-L1 contributes to immunosuppression and is associated with anti-PD-1 response. Nature, 560, 382-386.

Cho, J.H., Gelinas, R., Wang, K., Etheridge, A., Piper, M.G., Batte, K., Dakhallah, D., Price, J., Bornman, D., Zhang, S., Marsh, C. \& Galas, D. (2011) Systems biology of interstitial lung diseases: integration of mRNA and microRNA expression changes. BMC Med. Genomics, 4, 8.

Confalonieri, M., Salton, F. \& Fabiano, F. (2017) Acute respiratory distress syndrome. Eur. Respir. Rev., 26, 160116.

Danilov, S., Jaspard, E., Churakova, T., Towbin, H., Savoie, F., Wei, L. \& Alhenc-Gelas, F. (1994) Structure-function analysis of angiotensin I-converting enzyme using monoclonal antibodies. Selective inhibition of the amino-terminal active site. J. Biol. Chem., 269, 26806-26814.

Danilov, S.M., Gavrilyuk, V.D., Franke, F.E., Pauls, K., Harshaw, D.W., McDonald, T.D., Miletich, D.J. \& Muzykantov, V.R. (2001) Lung uptake of antibodies to endothelial antigens: key determinants of vascular immunotargeting. Am. J. Physiol. Lung Cell Mol. Physiol., 280, L1335-1347.

Delorme-Axford, E., Donker, R.B., Mouillet, J.F., Chu, T., Bayer, A., Ouyang, Y., Wang, T., Stolz, D.B., Sarkar, S.N., Morelli, A.E., Sadovsky, Y. \& Coyne, C.B. (2013) Human placental trophoblasts confer viral resistance to recipient cells. Proc. Natl. Acad. Sci. USA, 110, 12048-12053.

Djuranovic, S., Nahvi, A. \& Green, R. (2011) A parsimonious model for gene regulation by miRNAs. Science, 331, 550-553.

Faure, V., Dou, L., Sabatier, F., Cerini, C., Sampol, J., Berland, Y., Brunet, P. \& Dignat-George, F. (2006) Elevation of circulating endothelial microparticles in patients with chronic renal failure. J. Thromb. Haemost., 4, 566-573.

Feng, B., Chen, Y., Luo, Y., Chen, M., Li, X. \& Ni, Y. (2010) Circulating level of microparticles and their correlation with arterial elasticity and endothelium-dependent dilation in patients with type 2 diabetes mellitus. Atherosclerosis, 208, 264-269.

Gordon, C., Gudi, K., Krause, A., Sackrowitz, R., Harvey, B.G., Strulovici-Barel, Y., Mezey, J.G. \& Crystal, R.G. (2011) Circulating endothelial microparticles as a measure of early lung destruction in cigarette smokers. Am. J. Respir. Crit. Care Med., 184, 224-232.

Gregory, P.A., Bert, A.G., Paterson, E.L., Barry, S.C., Tsykin, A., Farshid, G., Vadas, M.A., Khew-Goodall, Y. \& Goodall, G.J. (2008) The miR-200 family and miR-205 regulate epithelial to mesenchymal transition by targeting ZEB1 and SIP1. Nat. Cell Biol., 10, 593-601.

György, B., Szabó, T.G., Pásztói, M., Pál, Z., Misják, P., Aradi, B., László, V., Pállinger, E., Pap, E., Kittel, A., Nagy, G., Falus, A. \& Buzás, E.I. (2011) Membrane vesicles, current state-of-theart: emerging role of extracellular vesicles. Cell. Mol. Life Sci., 68, 2667-2688

Han, J., Lee, Y., Yeom, K.H., Kim, Y.K., Jin, H. \& Kim, V.N. (2004) The Drosha-DGCR8 complex in primary microRNA processing. Genes Dev., 18, 3016-3027.

Hayashi, T., Koyama, N., Azuma, Y. \& Kashimata, M. (2011) Mesenchymal miR-21 regulates branching morphogenesis in murine submandibular gland in vitro. Dev. Biol., 352, 299-307.

Heukels, P., Moor, C.C., von der Thusen, J.H., Wijsenbeek, M.S. \& Kool, M. (2019) Inflammation and immunity in IPF pathogenesis and treatment. Respir. Med., 147, 79-91.

Huang, C., Xiao, X., Yang, Y., Mishra, A., Liang, Y., Zeng, X.,
Yang, X., Xu, D., Blackburn, M.R., Henke, C.A. \& Liu, L. (2017) MicroRNA-101 attenuates pulmonary fibrosis by inhibiting fibroblast proliferation and activation. J. Biol. Chem., 292, 16420-16439.

Hutvágner, G., McLachlan, J., Pasquinelli, A.E., Bálint, E., Tuschl, T. \& Zamore, P.D. (2001) A cellular function for the RNAinterference enzyme Dicer in the maturation of the let-7 small temporal RNA. Science, 293, 834-838.

Ismail, N., Wang, Y., Dakhlallah, D., Moldovan, L., Agarwal, K., Batte, K., Shah, P., Wisler, J., Eubank, T.D., Tridandapani, S., Paulaitis, M.E., Piper, M.G. \& Marsh, C.B. (2013) Macrophage microvesicles induce macrophage differentiation and miR-223 transfer. Blood, 121, 984-995.

Jiang, Z., Cushing, L., Ai, X. \& Lu, J. (2014) miR-326 is downstream of sonic hedgehog signaling and regulates the expression of Gli2 and smoothened. Am. J. Respir. Cell Mol. Biol., $\mathbf{5 1}, 273-283$.

Jung, C., Sorensson, P., Saleh, N., Arheden, H., Ryden, L. \& Pernow, J. (2012) Circulating endothelial and platelet derived microparticles reflect the size of myocardium at risk in patients with ST-elevation myocardial infarction. Atherosclerosis, 221, 226-231.

Kesimer, M., Scull, M., Brighton, B., DeMaria, G., Burns, K., O’Neal, W., Pickles, R.J. \& Sheehan, J.K. (2009) Characterization of exosome-like vesicles released from human tracheobronchial ciliated epithelium: a possible role in innate defense. FASEB J., 23, 1858-1868.

Ketting, R.F., Fischer, S.E., Bernstein, E., Sijen, T., Hannon, G.J. \& Plasterk, R.H. (2001) Dicer functions in RNA interference and in synthesis of small RNA involved in developmental timing in C. elegans. Genes Dev., 15, 2654-2659.

Kim, V.N. (2004) MicroRNA precursors in motion: exportin-5 mediates their nuclear export. Trends Cell Biol., 14, 156-159.

Kobayashi, S., Kubo, H., Suzuki, T., Ishizawa, K., Yamada, M., He, M., Yamamoto, Y., Yamamoto, H., Sasano, H., Sasaki, H. \& Suzuki, S. (2007) Endogenous secretory receptor for advanced glycation end products in non-small cell lung carcinoma. Am. J. Respir. Crit. Care Med., 175, 184-189.

Kosaka, N., Iguchi, H., Yoshioka, Y., Takeshita, F., Matsuki, Y. \& Ochiya, T. (2010) Secretory mechanisms and intercellular transfer of microRNAs in living cells. J. Biol. Chem., 285, 17442-17452.

Kosaka, N., Yoshioka, Y., Tominaga, N., Hagiwara, K., Katsuda, T. \& Ochiya, T. (2014) Dark side of the exosome: the role of the exosome in cancer metastasis and targeting the exosome as a strategy for cancer therapy. Future Oncol., 10, 671-681.

Kozomara, A., Birgaoanu, M. \& Griffiths-Jones, S. (2019) miRBase: from microRNA sequences to function. Nucleic Acids Res., 47, D155-D162.

Lagos-Quintana, M., Rauhut, R., Lendeckel, W. \& Tuschl, T. (2001) Identification of novel genes coding for small expressed RNAs. Science, 294, 853-858.

Lai, F.W., Lichty, B.D. \& Bowdish, D.M. (2015) Microvesicles: ubiquitous contributors to infection and immunity. J. Leukoc. Biol., 97, 237-245.

Lau, N.C., Lim, L.P., Weinstein, E.G. \& Bartel, D.P. (2001) An abundant class of tiny RNAs with probable regulatory roles in Caenorhabditis elegans. Science, 294, 858-862.

Lee, R.C. \& Ambros, V. (2001) An extensive class of small RNAs in Caenorhabditis elegans. Science, 294, 862-864.

Lee, R.C., Feinbaum, R.L. \& Ambros, V. (1993) The C. elegans heterochronic gene lin-4 encodes small RNAs with antisense complementarity to lin-14. Cell, 75, 843-854.

Lee, Y., Jeon, K., Lee, J.T., Kim, S. \& Kim, V.N. (2002) MicroRNA maturation: stepwise processing and subcellular localization. EMBO J., 21, 4663-4670.

Lee, Y., Kim, M., Han, J., Yeom, K.H., Lee, S., Baek, S.H. \& Kim, V.N. (2004) MicroRNA genes are transcribed by RNA polymerase II. EMBO J., 23, 4051-4060. 
Liu, B., Du, R., Zhou, L., Xu, J., Chen, S., Chen, J., Yang, X., Liu, D.X., Shao, Z.M., Zhang, L., Yu, Z., Xie, N., Guan, J.L. \& Liu, S. (2018) miR-200c/141 regulates breast cancer stem cell heterogeneity via targeting HIPK1/beta-catenin axis. Theranostics, 8, 5801-5813.

Liu, G., Friggeri, A., Yang, Y., Milosevic, J., Ding, Q., Thannickal, V.J., Kaminski, N. \& Abraham, E. (2010) miR-21 mediates fibrogenic activation of pulmonary fibroblasts and lung fibrosis. J. Exp. Med., 207, 1589-1597.

Lu, Y., Thomson, J.M., Wong, H.Y., Hammond, S.M. \& Hogan, B.L. (2007) Transgenic over-expression of the microRNA miR-17-92 cluster promotes proliferation and inhibits differentiation of lung epithelial progenitor cells. Dev. Biol., 310, 442-453.

Makiguchi, T., Yamada, M., Yoshioka, Y., Sugiura, H., Koarai, A., Chiba, S., Fujino, N., Tojo, Y., Ota, C., Kubo, H., Kobayashi, S., Yanai, M., Shimura, S., Ochiya, T. \& Ichinose, M. (2016) Serum extracellular vesicular miR-21-5p is a predictor of the prognosis in idiopathic pulmonary fibrosis. Respir. Res., 17, 110.

Martin-Medina, A., Lehmann, M., Burgy, O., Hermann, S., Baarsma, H.A., Wagner, D.E., De Santis, M.M., Ciolek, F., Hofer, T.P., Frankenberger, M., Aichler, M., Lindner, M., Gesierich, W., Guenther, A., Walch, A., et al. (2018) Increased extracellular vesicles mediate WNT5A signaling in idiopathic pulmonary fibrosis. Am. J. Respir. Crit. Care Med., 198, $1527-1538$.

Matthay, M.A. \& Zimmerman, G.A. (2005) Acute lung injury and the acute respiratory distress syndrome: four decades of inquiry into pathogenesis and rational management. Am. J. Respir. Cell Mol. Biol., 33, 319-327.

Melling, G.E., Carollo, E., Conlon, R., Simpson, J.C. \& Carter, D.R.F. (2019) The challenges and possibilities of extracellular vesicles as therapeutic vehicles. Eur. J. Pharm. Biopharm., 144, 50-56.

Menezes, S.L., Bozza, P.T., Neto, H.C., Laranjeira, A.P., Negri, E.M., Capelozzi, V.L., Zin, W.A. \& Rocco, P.R. (2005) Pulmonary and extrapulmonary acute lung injury: inflammatory and ultrastructural analyses. J. Appl. Physiol. (1985), 98, $1777-1783$

Meziani, F., Delabranche, X., Asfar, P. \& Toti, F. (2010) Bench-tobedside review: circulating microparticles: a new player in sepsis? Crit. Care, 14, 236.

Miao, C., Xiong, Y., Zhang, G. \& Chang, J. (2018) MicroRNAs in idiopathic pulmonary fibrosis, new research progress and their pathophysiological implication. Exp. Lung Res., 44, 178-190.

Moimas, S., Salton, F., Kosmider, B., Ring, N., Volpe, M.C., Bahmed, K., Braga, L., Rehman, M., Vodret, S., Graziani, M.L., Wolfson, M.R., Marchetti, N., Rogers, T.J., Giacca, M., Criner, G.J., et al. (2019) miR-200 family members reduce senescence and restore idiopathic pulmonary fibrosis type II alveolar epithelial cell transdifferentiation. ERJ Open Res., 5, 00138-2019.

Moon, H.G., Cao, Y., Yang, J., Lee, J.H., Choi, H.S. \& Jin, Y. (2015) Lung epithelial cell-derived extracellular vesicles activate macrophage-mediated inflammatory responses via ROCK1 pathway. Cell Death Dis., 6, e2016.

Morrison, T.J., Jackson, M.V., Cunningham, E.K., Kissenpfennig, A., McAuley, D.F., O'Kane, C.M. \& Krasnodembskaya, A.D. (2017) Mesenchymal stromal cells modulate macrophages in clinically relevant lung injury models by extracellular vesicle mitochondrial transfer. Am. J. Respir. Crit. Care Med., 196, 1275-1286

Neudecker, V., Brodsky, K.S., Clambey, E.T., Schmidt, E.P., Packard, T.A., Davenport, B., Standiford, T.J., Weng, T., Fletcher, A.A., Barthel, L., Masterson, J.C., Furuta, G.T., Cai, C., Blackburn, M.R., Ginde, A.A., et al. (2017) Neutrophil transfer of miR-223 to lung epithelial cells dampens acute lung injury in mice. Sci. Transl. Med., 9, eaah5360.
Nie, D.M., Wu, Q.L., Zheng, P., Chen, P., Zhang, R., Li, B.B., Fang, J., Xia, L.H. \& Hong, M. (2016) Endothelial microparticles carrying hedgehog-interacting protein induce continuous endothelial damage in the pathogenesis of acute graft-versushost disease. Am. J. Physiol. Cell Physiol., 310, C821-835.

Nishida-Aoki, N. \& Ochiya, T. (2015) Interactions between cancer cells and normal cells via miRNAs in extracellular vesicles. Cell. Mol. Life Sci., 72, 1849-1861.

Nozaki, T., Sugiyama, S., Koga, H., Sugamura, K., Ohba, K., Matsuzawa, Y., Sumida, H., Matsui, K., Jinnouchi, H. \& Ogawa, H. (2009) Significance of a multiple biomarkers strategy including endothelial dysfunction to improve risk stratification for cardiovascular events in patients at high risk for coronary heart disease. J. Am. Coll. Cardiol., 54, 601-608.

Oak, S.R., Murray, L., Herath, A., Sleeman, M., Anderson, I., Joshi, A.D., Coelho, A.L., Flaherty, K.R., Toews, G.B., Knight, D., Martinez, F.J. \& Hogaboam, C.M. (2011) A micro RNA processing defect in rapidly progressing idiopathic pulmonary fibrosis. PLoS One, 6, e21253.

Ohno, M., Matsuzaki, J., Kawauchi, J., Aoki, Y., Miura, J., Takizawa, S., Kato, K., Sakamoto, H., Matsushita, Y., Takahashi, M., Miyakita, Y., Ichimura, K., Narita, Y. \& Ochiya, T. (2019) Assessment of the diagnostic utility of serum microRNA classification in patients with diffuse glioma. JAMA Netw. Open, 2, e1916953.

Pan, X., Wang, Z.X. \& Wang, R. (2010) MicroRNA-21: a novel therapeutic target in human cancer. Cancer Biol. Ther., 10, 1224-1232.

Pandit, K.V., Corcoran, D., Yousef, H., Yarlagadda, M., Tzouvelekis, A., Gibson, K.F., Konishi, K., Yousem, S.A., Singh, M., Handley, D., Richards, T., Selman, M., Watkins, S.C., Pardo, A., Ben-Yehudah, A., et al. (2010) Inhibition and role of let-7d in idiopathic pulmonary fibrosis. Am. J. Respir. Crit. Care Med., 182, 220-229.

Park, J.H. \& Shin, C. (2014) MicroRNA-directed cleavage of targets: mechanism and experimental approaches. BMB Rep., 47, 417-423.

Pegtel, D.M., Cosmopoulos, K., Thorley-Lawson, D.A., van Eijndhoven, M.A., Hopmans, E.S., Lindenberg, J.L., de Gruijl, T.D., Würdinger, T. \& Middeldorp, J.M. (2010) Functional delivery of viral miRNAs via exosomes. Proc. Natl. Acad. Sci. USA, 107, 6328-6333.

Pegtel, D.M. \& Gould, S.J. (2019) Exosomes. Annu. Rev. Biochem., 88, 487-514.

Pelosi, P., D’Onofrio, D., Chiumello, D., Paolo, S., Chiara, G., Capelozzi, V.L., Barbas, C.S., Chiaranda, M. \& Gattinoni, L. (2003) Pulmonary and extrapulmonary acute respiratory distress syndrome are different. Eur. Respir. J. Suppl., 42, $48 \mathrm{~s}-56 \mathrm{~s}$.

Rao, R., Rieder, S.A., Nagarkatti, P. \& Nagarkatti, M. (2014) Staphylococcal enterotoxin B-induced microRNA-155 targets SOCS1 to promote acute inflammatory lung injury. Infect. Immun., 82, 2971-2979.

Raposo, G. \& Stoorvogel, W. (2013) Extracellular vesicles: exosomes, microvesicles, and friends. J. Cell Biol., 200, 373-383.

Richeldi, L., Collard, H.R. \& Jones, M.G. (2017) Idiopathic pulmonary fibrosis. Lancet, 389, 1941-1952.

Rissland, O.S., Subtelny, A.O., Wang, M., Lugowski, A., Nicholson, B., Laver, J.D., Sidhu, S.S., Smibert, C.A., Lipshitz, H.D. \& Bartel, D.P. (2017) The influence of microRNAs and poly(A) tail length on endogenous mRNA-protein complexes. Genome Biol., 18, 211.

Schiro, A., Wilkinson, F.L., Weston, R., Smyth, J.V., SerracinoInglott, F. \& Alexander, M.Y. (2014) Endothelial microparticles as conveyors of information in atherosclerotic disease. Atherosclerosis, 234, 295-302.

Schwarz, D.S., Hutvágner, G., Du, T., Xu, Z., Aronin, N. \& Zamore, P.D. (2003) Asymmetry in the assembly of the RNAi 
enzyme complex. Cell, 115, 199-208.

Sgalla, G., Iovene, B., Calvello, M., Ori, M., Varone, F. \& Richeldi, L. (2018) Idiopathic pulmonary fibrosis: pathogenesis and management. Respir. Res., 19, 32.

Shaver, C.M. \& Bastarache, J.A. (2014) Clinical and biological heterogeneity in acute respiratory distress syndrome: direct versus indirect lung injury. Clin. Chest Med., 35, 639-653.

Shukla, G.C., Singh, J. \& Barik, S. (2011) MicroRNAs: processing, maturation, target recognition and regulatory functions. Mol. Cell. Pharmacol., 3, 83-92.

Sudo, K., Kato, K., Matsuzaki, J., Boku, N., Abe, S., Saito, Y., Daiko, H., Takizawa, S., Aoki, Y., Sakamoto, H., Niida, S., Takeshita, F., Fukuda, T. \& Ochiya, T. (2019) Development and validation of an esophageal squamous cell carcinoma detection model by large-scale microRNA profiling. JAMA Netw. Open, 2, e194573.

Sun, J., Li, Q., Lian, X., Zhu, Z., Chen, X., Pei, W., Li, S., Abbas, A., Wang, Y. \& Tian, L. (2019) MicroRNA-29b mediates lung mesenchymal-epithelial transition and prevents lung fibrosis in the silicosis model. Mol. Ther. Nucleic Acids, 14, 20-31.

Sun, X., Icli, B., Wara, A.K., Belkin, N., He, S., Kobzik, L., Hunninghake, G.M., Vera, M.P., Registry, M., Blackwell, T.S., Baron, R.M. \& Feinberg, M.W. (2012) MicroRNA-181b regulates NF-kappaB-mediated vascular inflammation. $J$. Clin. Invest., 122, 1973-1990.

Suzuki, T., Suzuki, S., Fujino, N., Ota, C., Yamada, M., Suzuki, T., Yamaya, M., Kondo, T. \& Kubo, H. (2014) c-Kit immunoexpression delineates a putative endothelial progenitor cell population in developing human lungs. Am. J. Physiol. Lung Cell Mol. Physiol., 306, L855-865.

Takahashi, T., Kobayashi, S., Fujino, N., Suzuki, T., Ota, C., He, M., Yamada, M., Suzuki, S., Yanai, M., Kurosawa, S., Yamaya, M. \& Kubo, H. (2012) Increased circulating endothelial microparticles in COPD patients: a potential biomarker for COPD exacerbation susceptibility. Thorax, 67, 1067-1074.

Takahashi, T., Kobayashi, S., Fujino, N., Suzuki, T., Ota, C., Tando, Y., He, M., Yamada, M., Kurosawa, S., Yamaya, M. \& Kubo, H. (2013) Differences in the released endothelial microparticle subtypes between human pulmonary microvascular endothelial cells and aortic endothelial cells in vitro. Exp. Lung Res., 39, 155-161.

Takei, Y., Yamada, M., Saito, K., Kameyama, Y., Sugiura, H., Makiguchi, T., Fujino, N., Koarai, A., Toyama, H., Saito, K., Ejima, Y., Kawazoe, Y., Kudo, D., Kushimoto, S., Yamauchi, M., et al. (2019) Increase in circulating ACE-positive endothelial microparticles during acute lung injury. Eur. Respir. J., 54, 1801188

Title, A.C., Hong, S.J., Pires, N.D., Hasenöhrl, L., Godbersen, S., Stokar-Regenscheit, N., Bartel, D.P. \& Stoffel, M. (2018) Genetic dissection of the miR-200-Zeb1 axis reveals its importance in tumor differentiation and invasion. Nat. Commun., 9, 4671

Valadi, H., Ekström, K., Bossios, A., Sjöstrand, M., Lee, J.J. \& Lötvall, J.O. (2007) Exosome-mediated transfer of mRNAs and microRNAs is a novel mechanism of genetic exchange between cells. Nat. Cell Biol., 9, 654-659.

Valencia-Sanchez, M.A., Liu, J., Hannon, G.J. \& Parker, R. (2006) Control of translation and mRNA degradation by miRNAs and siRNAs. Genes Dev., 20, 515-524.

Vannella, K.M. \& Wynn, T.A. (2017) Mechanisms of organ injury and repair by macrophages. Annu. Rev. Physiol., 79, 593-617.

Vergadi, E., Vaporidi, K., Theodorakis, E.E., Doxaki, C., Lagoudaki, E., Ieronymaki, E., Alexaki, V.I., Helms, M., Kondili, E., Soennichsen, B., Stathopoulos, E.N., Margioris, A.N., Georgopoulos, D. \& Tsatsanis, C. (2014) Akt2 deficiency protects from acute lung injury via alternative macrophage activation and miR-146a induction in mice. J. Immunol., 192, 394-406.

Vlassov, A.V., Magdaleno, S., Setterquist, R. \& Conrad, R. (2012) Exosomes: current knowledge of their composition, biological functions, and diagnostic and therapeutic potentials. Biochim. Biophys. Acta, 1820, 940-948.

Waldenstrom, A. \& Ronquist, G. (2014) Role of exosomes in myocardial remodeling. Circ. Res., 114, 315-324.

Wang, C., Senapati, S. \& Chang, H.C. (2020) Liquid biopsy technologies based on membrane microfluidics: High-yield purification and selective quantification of biomarkers in nanocarriers. Electrophoresis, doi: 10.1002/elps.202000015.[Epub ahead of print].

Wiklander, O.P.B., Brennan, M.Á., Lötvall J., Breakefield, X.O. \& El Andaloussi, S. (2019) Advances in therapeutic applications of extracellular vesicles. Sci. Transl. Med., 11, eaav8521.

Witwer, K.W. \& Thery, C. (2019) Extracellular vesicles or exosomes? On primacy, precision, and popularity influencing a choice of nomenclature. J. Extracell. Vesicles, 8, 1648167.

Yamada, M., Kubo, H., Ota, C., Takahashi, T., Tando, Y., Suzuki, T., Fujino, N., Makiguchi, T., Takagi, K., Suzuki, T. \& Ichinose, M. (2013) The increase of microRNA-21 during lung fibrosis and its contribution to epithelial-mesenchymal transition in pulmonary epithelial cells. Respir. Res., 14, 95.

Yáñez-Mó, M., Siljander, P.R., Andreu, Z., Zavec, A.B., Borràs, F.E., Buzas, E.I., Buzas, K., Casal, E., Cappello, F., Carvalho, J., Colás, E., Cordeiro-da Silva, A., Fais, S., Falcon-Perez, J.M., Ghobrial, I.M., et al. (2015) Biological properties of extracellular vesicles and their physiological functions. $J$. Extracell. Vesicles, 4, 27066.

Yang, S., Banerjee, S., de Freitas, A., Sanders, Y.Y., Ding, Q., Matalon, S., Thannickal, V.J., Abraham, E. \& Liu, G. (2012) Participation of miR-200 in pulmonary fibrosis. Am. J. Pathol., 180, 484-493.

Yeom, K.H., Lee, Y., Han, J., Suh, M.R. \& Kim, V.N. (2006) Characterization of DGCR8/Pasha, the essential cofactor for Drosha in primary miRNA processing. Nucleic Acids Res., 34, 4622-4629.

Yokoi, A., Matsuzaki, J., Yamamoto, Y., Yoneoka, Y., Takahashi, K., Shimizu, H., Uehara, T., Ishikawa, M., Ikeda, S.I., Sonoda, T., Kawauchi, J., Takizawa, S., Aoki, Y., Niida, S., Sakamoto, H., et al. (2018) Integrated extracellular microRNA profiling for ovarian cancer screening. Nat. Commun., 9, 4319.

Yoshioka, Y., Konishi, Y., Kosaka, N., Katsuda, T., Kato, T. \& Ochiya, T. (2013) Comparative marker analysis of extracellular vesicles in different human cancer types. J. Extracell. Vesicles, 2, 20424.

Yoshioka, Y., Kosaka, N., Konishi, Y., Ohta, H., Okamoto, H., Sonoda, H., Nonaka, R., Yamamoto, H., Ishii, H., Mori, M., Furuta, K., Nakajima, T., Hayashi, H., Sugisaki, H., Higashimoto, H., et al. (2014) Ultra-sensitive liquid biopsy of circulating extracellular vesicles using ExoScreen. Nat. Commun., $\mathbf{5}, 3591$.

Yun, J.W., Xiao, A., Tsunoda, I., Minagar, A. \& Alexander, J.S. (2016) From trash to treasure: the untapped potential of endothelial microparticles in neurovascular diseases. Pathophysio$\log y, 23,265-274$.

Zemans, R.L., Briones, N., Campbell, M., McClendon, J., Young, S.K., Suzuki, T., Yang, I.V., De Langhe, S., Reynolds, S.D., Mason, R.J., Kahn, M., Henson, P.M., Colgan, S.P. \& Downey, G.P. (2011) Neutrophil transmigration triggers repair of the lung epithelium via beta-catenin signaling. Proc. Natl. Acad. Sci. USA, 108, 15990-15995.

Zemans, R.L., Henson, P.M., Henson, J.E. \& Janssen, W.J. (2015) Conceptual approaches to lung injury and repair. Ann. Am. Thorac. Soc., 12 Suppl 1, S9-15.

Zeng, Z., Gong, H., Li, Y., Jie, K., Ding, C., Shao, Q., Liu, F., Zhan, Y., Nie, C., Zhu, W. \& Qian, K. (2013) Upregulation of miR-146a contributes to the suppression of inflammatory responses in LPS-induced acute lung injury. Exp. Lung Res., 39, 275-282.

Zhang, Y., Liu, D., Chen, X., Li, J., Li, L., Bian, Z., Sun, F., Lu, J., Yin, Y., Cai, X., Sun, Q., Wang, K., Ba, Y., Wang, Q., Wang, 
D., et al. (2010) Secreted monocytic miR-150 enhances targeted endothelial cell migration. Mol. Cell, 39, 133-144.

Zhu, Y.G., Feng, X.M., Abbott, J., Fang, X.H., Hao, Q., Monsel, A., Qu, J.M., Matthay, M.A. \& Lee, J.W. (2014) Human mesenchymal stem cell microvesicles for treatment of Escherichia coli endotoxin-induced acute lung injury in mice. Stem Cells, 32, 116-125.

Zhu, Z., Liang, L., Zhang, R., Wei, Y., Su, L., Tejera, P., Guo, Y., Wang, Z., Lu, Q., Baccarelli, A.A., Zhu, X., Bajwa, E.K.,
Taylor Thompson, B., Shi, G.P. \& Christiani, D.C. (2017) Whole blood microRNA markers are associated with acute respiratory distress syndrome. Intensive Care Med. Exp., 5, 38.

Zhu, Z., Zhang, R., Liang, L., Su, L., Lu, Q., Baccarelli, A.A., Bajwa, E.K., Thompson, B.T. \& Christiani, D.C. (2016) Whole blood microRNAs as a prognostic classifier for acute respiratory distress syndrome 28 -day mortality. Intensive Care Med., 42, 1824-1825. 